\title{
Sensitive Determination of Quinones by High-Performance Liquid Chromatography-Electrospray Ionization-Tandem Mass Spectrometry with Methanol Derivatization
}

\author{
Jiying PEI, ${ }^{* * *}$ Yinghui WANG, ${ }^{*, * * \dagger}$ and Kefu YU ${ }^{*, * * \dagger}$ \\ *School of Marine Sciences, Guangxi University, Nanning, 53004, P. R. China \\ **Coral Reef Research Center of China, Nanning, 53004, P. R. China
}

\begin{abstract}
Quinones are a class of compounds having substantial toxicity and pharmacological function. This work has produced a derivatization method for quinone detection with high-performance liquid chromatography-electrospray ionization-tandem mass spectrometry (HPLC-ESI-MS/MS). Through introducing tags (methoxy) to the quinone structures, the ionization efficiencies of five quinones ( $p$-benzoquinone (BQ), methyl-p-benzoquinone (MBQ), 1,4-naphthoquinone (1,4-NQ), 1,2-naphthoquinone (1,2-NQ), and 1,4-anthraquinones (AQ)) were greatly improved during ESI. The limit of detections (LODs) for quinone determination could be flexibly adjusted by changing the reaction time or the solvent composition. While lower LODs $(<0.02-2.06 \mathrm{pg}$ for five quinones) were achieved with methanol as the derivatization reagent, the reaction time was substantially shortened (from 27 to $3 \mathrm{~h}$ or $11 \mathrm{~h}$ ) with methanol/water $(\mathrm{v} / \mathrm{v}, 1: 1)$ as the derivatization reagent. Finally, the proposed method was successfully used for quinone determination in airborne particulates.
\end{abstract}

Keywords Quinone, methanol derivatization, electrospray, mass spectrometry, PM2.5

(Received August 8, 2017; Accepted October 31, 2017; Published March 10, 2018)

\section{Introduction}

Quinones are indispensable ingredients to maintain the life activities of animals and plants, and are important constituents of certain clinical drugs. For example, ubiquinone and plastoquinone participate in life metabolic activities through redox cycles; $;^{1-4}$ pyrroloquinoline quinone is an essential constituent substrate for various dehydrogenase enzymes in bacteria $;{ }^{5}$ rhein derivatives and doxorubicin are used as antiinflammatory ${ }^{6}$ and anti-tumor agents, ${ }^{7}$ respectively. In addition, quinones are harmful to human health due to their ability to form covalent bonds with biomacromolecules and to generate reactive oxygen species (ROSs) that can induce mutations and cancer. ${ }^{8,9}$ Numerous studies have shown that the redox activity of urban airborne particulate matter is related to quinones and transition metals. ${ }^{10-12}$ 9,10-Phenanthrenequinone can both inhibit nitric oxide synthase activity ${ }^{13}$ and disrupt progesterone production in vivo. ${ }^{14}$ Therefore, it is highly desired to develop sensitive methods for quinone determination in various fields.

Various analytical methods, including spectrophotometry, ${ }^{15}$ electrochemistry, ${ }^{16}$ and high-performance liquid chromatography (HPLC) with ultraviolet, $^{17}$ fluorescence ${ }^{18-20}$ and chemiluminiscence detectors, ${ }^{17,21,22}$ have been applied for quinone determination. Based on postcolumn fluorescence derivatization or chemiluminiscence, Kuroda and Kameda's group developed a series of methods for quinone determination. ${ }^{17,19-24}$ Though HPLC instruments are available to

† To whom correspondence should be addressed.

E-mail: wyh@gxu.edu.cn; kefuyu@ @csio.ac.cn most laboratories, further applications are restricted for the high limit of detection (LOD). The mass spectrometer is a highly sensitive detector; however, determinations are more restricted to the atmospheric pressure chemical ionization (APCI) source for the low ionization efficiencies of quinones in electrospray ionization (ESI). ${ }^{25-27}$ To improve the ionization efficiencies of quinones in ESI, a mercapto-reagent was used to label them, ${ }^{28}$ and in situ detection from complex matrixes was achieved by employing a paper spray. Gas chromatography-mass spectrometry (GC-MS) is highly sensitive for quinone determination. However, due to the high polarity and low vapor pressure of quinones, derivatizations with a complex organic reagent, ${ }^{25}$ such as $O$-(2,3,4,5,6-pentafluorobenzyl) hydroxylamine (PFBHA), ${ }^{29}$ or 4-dinitrophenylhydrazone (DNPH), ${ }^{30}$ are generally obligatory. Toriba et al. developed a highly sensitive GC-MS/MS method for quinone detection though derivatization with mixed silylation reagent (BSA:TMCS:TMSI, 3:2:3), and extremely low LODs (1.2 - $29 \mathrm{fg}$ /injection) were achieved for 37 polycyclic aromatic hydrocarbon quinones (PAHQs). ${ }^{31}$ However, the complex experiment procedures would demand a more professional staff, constraining the popularization. Therefore, more simple and sensitive methods for quinone determination are still needed.

Herein, we describe our simple and economic HPLC-ESI-MS/ MS method for quinone determination with methanol derivatization. Two important reaction parameters, the reaction time and reaction solvent, were optimized for five quinones ( $p$-benzoquinone, $\mathrm{BQ}$; methyl- $p$-benzoquinone, $\mathrm{MBQ}$; 1,4-naphthoquinone, 1,4-NQ; 1,2-naphthoquinone, 1,2-NQ; 1,4-anthraquinones, AQ) determination. Then, the developed method was applied for quinone determination in airborne particulate matter (PM2.5) collected at Nanning city. 


\section{Experimental}

\section{Reagents and chemicals}

BQ, MBQ, 1,4-NQ, 1,2-NQ, AQ, and 2-methyl-1,4naphthoquinone (MNQ) were obtained from ANPEL Laboratory Technologies (Shanghai, China). All organic solvents (acetonitrile, methanol and dichloromethane) were of HPLC grade from Honeywell Burdick\&Jackson Inc. (USA). Ultrapure water was obtained from a Milli-Q water purification system (Millipore, Bedford, MA USA). Stock solutions of five quinones were prepared by dissolving the powder in acetonitrile to a concentration of $1000 \mu \mathrm{g} \mathrm{mL}^{-1}$ and preserved at $-20^{\circ} \mathrm{C}$. Standard solutions of quinone mixture were prepared by diluting the stock solution in methanol.

\section{$L C-M S / M S$}

An Agilent 1290 series LC system (Agilent Technologies, Palo Alto, CA) consisting of a binary pump and an autosampler was used for LC separation with an Agilent Zorbax Eclipse Plus C18 column $(50 \times 2.1 \mathrm{~mm}$ i.d., $1.8 \mu \mathrm{m}$; USA $)$ at $35^{\circ} \mathrm{C}$. The flow rate of the mobile phase was $0.2 \mathrm{~mL} \mathrm{~min}^{-1}$, and the injection volume was $2 \mu \mathrm{L}$. The initial mobile phase was $30 \% \mathrm{~A}$ (methanol) and $70 \% \mathrm{~B}$ (water containing $5 \mathrm{mmol} \mathrm{L}^{-1}$ ammonium acetate and $0.1 \% \mathrm{FA}$ ), followed by a linear gradient to $90 \% \mathrm{~A}$ in $3 \mathrm{~min}$, and kept isocratic for $2.5 \mathrm{~min}$, and then back to $30 \%$ A for $0.5 \mathrm{~min}$.

A triple quadrupole tandem mass spectrometer (Agilent 6460, USA) equipped with an electrospray ionization source was used. Unless stated otherwise, the mass spectrometer was operated in the positive ionization mode with multiple reaction monitoring (MRM). The ionization source parameters were set as follows: spray voltage, $3500 \mathrm{~V}$; curtain gas temperature, $350^{\circ} \mathrm{C}$; curtain gas flow, $8 \mathrm{~L} \mathrm{~min}^{-1}$; nebulizer gas flow, $40 \mathrm{psi}$; EMV, $0 \mathrm{~V}$. The compound-dependent parameters, including fragment energy (FE) and collision energy (CE), are presented in Table S1 in the supplementary material. High-resolution mass spectrometry was conducted using an Orbitrap Exactive Plus mass spectrometer (Thermo Fisher Scientific, San Jose, CA).

\section{Reaction dynamics of quinone derivatization with methanol}

Standard solutions of five quinone mixtures in methanol or methanol/water were subjected to air heating at $65^{\circ} \mathrm{C}$. An aliquot of sample solution was taken out for LC-MS/MS analysis at interval times (15 min - $12 \mathrm{~h})$.

\section{Sample collection and preparation}

PM2.5 was collected at the south gate of Guangxi University (China), which was $5 \mathrm{~m}$ away from a busy street with traffic on December 2th, 2016. Sampling was conducted using a highvolume air sampler equipped with a $2.5-\mu \mathrm{m}$ inlet (Andersen Instruments/GMW) with Whatman quartz microfiber filters $\left(20.3 \times 25.4 \mathrm{~cm}\right.$, preheated for $5 \mathrm{~h}$ at $\left.450^{\circ} \mathrm{C}\right)$ at a flow rate of $300 \mathrm{~L} \mathrm{~min}^{-1}$ for $24 \mathrm{~h}$. The filters with airborne particulates were stored in a refrigerator at $-20^{\circ} \mathrm{C}$ until analysis.

The filter $(5.1 \times 12.7 \mathrm{~cm})$ was extracted ultrasonically with $10 \mathrm{~mL}$ of a mixture of dichloromethane and methanol (v/v, 1:1) for $20 \mathrm{~min}$. After taking the organic layer, the extraction was repeated twice on the same filter. These organic layers were combined and concentrated to $\sim 2 \mathrm{~mL}$ by rotary evaporation, and then reduced to near dryness under a gentle nitrogen stream at $35^{\circ} \mathrm{C}$. The residue was dissolved in $1 \mathrm{~mL}$ methanol, and filtered with a $0.2-\mu \mathrm{m}$ filter unit (ANPEL Laboratory Technologies, Shanghai, China) into an autosampler vial for further derivatization reaction.

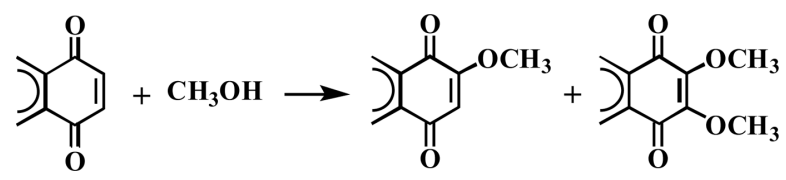

Scheme 1 Reaction equation between quinones and methanol.

The recovery experiments were carried out by spiking $50 \mathrm{ng}$ of $\mathrm{BQ}, \mathrm{MBQ}, 1,4-\mathrm{NQ}, \mathrm{AQ}$, and $5 \mathrm{ng}$ of 1,2-NQ to airborne particulate filter. After treatment, the recoveries were determined on the basis of the following equation: Recovery $(\%)=$ (concentration of prespiked sample - concentration of no-spiked sample)/concentration of standard sample. An external standard method was used to quantify quinones in PM2.5 with the concentration gradients of $0,2,5,10,20,50$ and $100 \mathrm{ng} \mathrm{mL}^{-1}$. The recovery rates of $\mathrm{BQ}, \mathrm{MBQ}, 1,4-\mathrm{NQ}, 1,2-\mathrm{NQ}$, and AQ were $31.1,47.3,21.2,50.1$, and $52.8 \%$, respectively.

\section{Results and Discussion}

\section{Derivatization of quinones with methanol}

The derivatization of quinones with methanol (Scheme 1) was inspired by the observation that $1,2-\mathrm{NQ}(\mathrm{m} / \mathrm{z}, 158)$ in methanol was substantially transformed to a species with $\mathrm{m} / \mathrm{z}, 189$ for six months' storage at $4{ }^{\circ} \mathrm{C}$ conditions (Fig. 1a, upper panel). The species with $\mathrm{m} / \mathrm{z}, 189$ was inferred to be a methanol derivative of 1,2-NQ on the basis of the characteristic MS/MS fragment ions (Fig. S1a). For freshly prepared 1,2-NQ in acetonitrile, however, the species could hardly be observed with ESI-MS analysis (Fig. 1a, lower panel). That meant that 1,2-NQ reacted with methanol in the liquid phase during the storage process. ${ }^{25}$ Compared with the signal intensity of 1,2-NQ without derivatization, the signal intensity of the 1,2-NQ derivative improved by as much as four times. Therefore, this inspired us to use methanol derivatization to improve the ionization efficiencies of quinones in ESI-MS.

The derivatization reaction between 1,2-NQ and methanol is a Michael addition reaction, similar to that occurring between quinones and cysteine. ${ }^{32,33}$ Though nearly all of the 1,2-NQ was transformed to the methanol derivatives within the six-month storage process at $4^{\circ} \mathrm{C}$, other quinones including $\mathrm{BQ}, \mathrm{MBQ}$, 1,4-NQ, AQ and MNQ were seldomly transformed. To test whether the reaction rate was related to temperature, we subjected the quinone mixture (BQ, MBQ, 1,4-NQ, AQ and $\mathrm{MNQ})$ in methanol to air heating $\left(65^{\circ} \mathrm{C}\right)$ for $24 \mathrm{~h}$. The results showed that BQ and MBQ were added with two methoxyls, whereas 1,4-NQ and AQ were added with one methoxyl, and MNQ hardly reacted with methanol (Fig. 1b). MS/MS spectra further verified the identifications of these species $\left(\mathrm{BQ}-2 \mathrm{OCH}_{3}\right.$, $m / z$ 169; $\mathrm{MBQ}-2 \mathrm{OCH}_{3}, m / z$ 183; $\mathrm{NQ}-\mathrm{OCH}_{3}, \mathrm{~m} / \mathrm{z}$ 189; AQ$\mathrm{OCH}_{3}, m / z$ 239) (Figs. S1b - S1e). The different derivatization behaviors of various quinones with methanol may be related to the structures of quinones. There are four, three, two, two, two, and one available carbon sites on the quinone ring of $B Q, M B Q$, 1,4-NQ, 1,2-NQ, AQ, and MNQ, respectively. Chemical structures with less steric hindrance may be more liable to nucleophilic addition, and the electronegativity of the available carbon on the quinone ring may also affect the reactive activation. Though both 1,2-NQ and 1,4-NQ possessed two available carbon sites on the quinone ring, the former more readily reacted with methanol, which could be attributed to the stronger electropositivity of the carbon in 1,2-NQ. The signal 


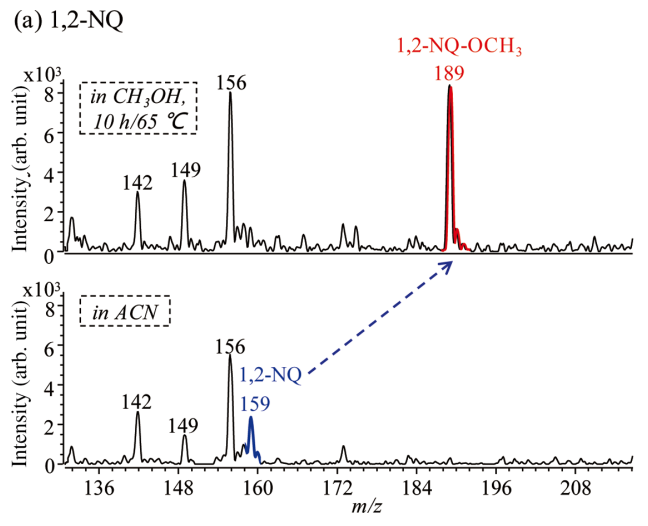

(b) BQ, MBQ, 1,4-NQ and AQ

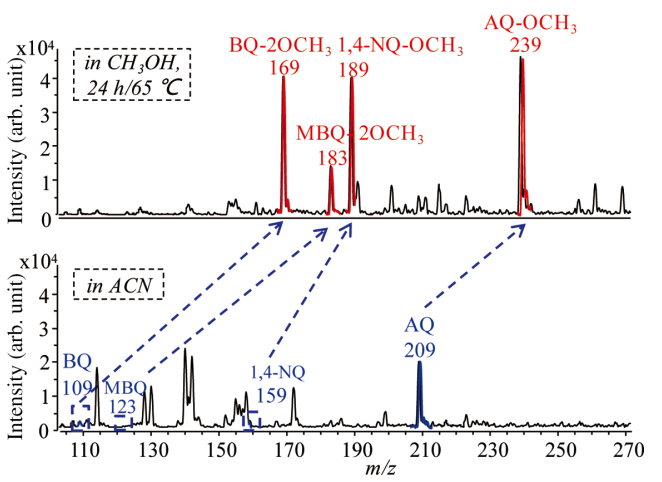

Fig. 1 Comparison of the mass spectra of (a) 1,2-NQ, (b) BQ, MBQ, 1,4-NQ and AQ in methanol $\left(\mathrm{CH}_{3} \mathrm{OH}\right.$, with derivatization) and acetonitrile (ACN, without derivatization) with ESI-MS analysis. The concentrations of 1,2-NQ and the other four quinones were $10 \mathrm{ng} \mathrm{mL}^{-1}$ and $1 \mu \mathrm{g} \mathrm{mL}^{-1}$, respectively.

responses of $\mathrm{BQ}, \mathrm{MBQ}$, and 1,4-NQ during ESI MS were fairly poor (Fig. 1b, lower panel); therefore, derivatization with methanol had greatly improved their signal intensities (Fig. 1b, upper panel). The derivatization of 1,2-NQ and AQ with methanol improved the signal intensity by about five times based on MS/MS, accompanying a decrease of the noise level by about two times. Therefore, the signal-to-noise ratios for 1,2-NQ and AQ determination could be improved by about one order of magnitude (Fig. S2).

Condition optimization of the derivatization reaction and performance characterization of the proposed HPLC-ESI-MS/ MS method

There are two important parameters that affect the reaction efficiencies of quinone derivatization: the reaction time and the reaction solvent.

The reaction kinetics curves of the five quinones with methanol are shown in Fig. 2. The reaction rates of $\mathrm{BQ}$ and 1,2-NQ were much higher than MBQ, 1,4-NQ, and AQ. While the reactions finished in $11 \mathrm{~h}$ for $\mathrm{BQ}$ and 1,2-NQ, it needed over $80 \mathrm{~h}$ for MBQ, 1,4-NQ, and AQ, and the reaction rates slowed down after $59 \mathrm{~h}$. With higher quinone concentrations (20 and $50 \mathrm{ng} \mathrm{mL}^{-1}$ ), the signal intensities of BQ and 1,2-NQ derivatives decayed after $27 \mathrm{~h}$. The linearity curves for the five quinones determination with reaction time of 27 and $59 \mathrm{~h}$ are shown in Fig. 3. The LODs of BQ, MBQ, 1,4-NQ, 1,2-NQ and AQ were $0.41,2.14,0.1,0.01$ and $0.1 \mathrm{ng}$, respectively, with the squared correlation coefficients $\left(R^{2}\right)$ ranging from 0.9950 to 0.9999 for reacting $27 \mathrm{~h}$ (Fig. 3a). The LOD decreased by two times for MBQ, while those of the other four quinones changed slightly for reacting $59 \mathrm{~h}$, accompanying the worse $R^{2}$ from 0.9611 to 0.9947 (Fig. 3b). Therefore, $27 \mathrm{~h}$ was suggested to be chosen as the reaction time for the simultaneous analysis of the five quinones from a comprehensive consideration of the reaction throughput and LOD.

Derivatization with mercapto-reagent was used to in situ determination of quinones from complex matrix by the paper spray in our previous work. However, the derivatization reaction was not applicable to LC-MS analysis, because the derivatives easily oxidized at room temperature during the detection process (Fig. S3). Our method was free from such interference, since the derivatives could stabilize at room temperature for over $36 \mathrm{~h}$ (Fig. S4).

The second parameter that affected the reaction efficiency of quinones with methanol was the reaction solvent composition.
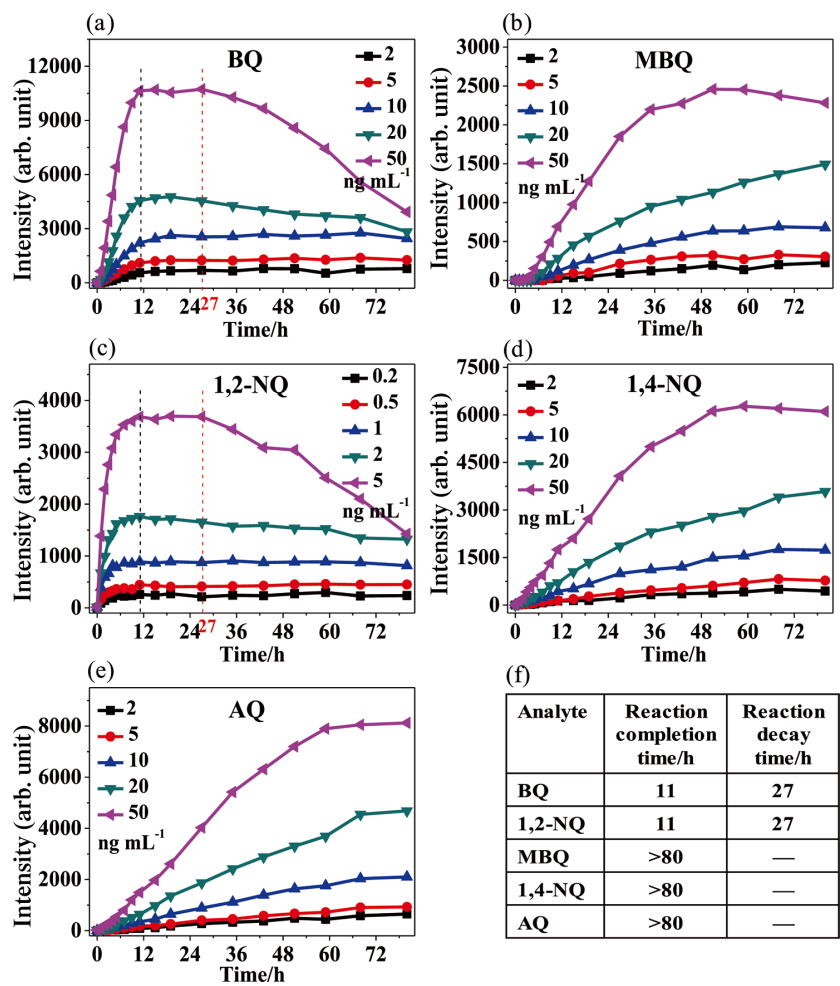

(f)

\begin{tabular}{|l|c|c|}
\hline Analyte & $\begin{array}{c}\text { Reaction } \\
\text { completion } \\
\text { time/h }\end{array}$ & $\begin{array}{c}\text { Reaction } \\
\text { decay } \\
\text { time/h }\end{array}$ \\
\hline BQ & 11 & 27 \\
\hline $\mathbf{1 , 2 - N Q}$ & 11 & 27 \\
\hline MBQ & $>80$ & - \\
\hline $1,4-N Q$ & $>80$ & - \\
\hline AQ & $>80$ & - \\
\hline
\end{tabular}

Fig. 2 Reaction dynamics curves of a) BQ, b) MBQ, c) 1,2-NQ, d) 1,4-NQ, and e) AQ with methanol derivatization, f) summary of the reaction completion time and decay time.

The reaction kinetics curves for the five quinones determination with methanol/water $(\mathrm{v} / \mathrm{v}, 1: 1)$ as the derivatization reagent are shown in Fig. 4. The reaction finished in 3, 11, 11, $3 \mathrm{~h}$, and $>15 \mathrm{~h}$ for $\mathrm{BQ}, \mathrm{MBQ}, 1,4-\mathrm{NQ}, 1,2-\mathrm{NQ}$, and AQ, respectively. Afterwards, the signal intensities of BQ and 1,2-NQ derivatives decreased. Though the derivatization reaction proceeded in $15 \mathrm{~h}$ for $\mathrm{AQ}$, the reaction rate slowed down after $11 \mathrm{~h}$. Therefore, the optimal time for $\mathrm{BQ}, 1,2-\mathrm{NQ}, \mathrm{MBQ}, 1,4-\mathrm{NQ}$, and $\mathrm{AQ}$ derivatization reaction could be chosen as 3 or $11 \mathrm{~h}$. The derivatives in methanol/water (v/v, 1:1) were also stable at room temperature after completion of the reaction (Fig. S5). Under the optimal conditions, the LODs for BQ, MBQ, 1,4-NQ, $1,2-\mathrm{NQ}$, and AQ determination were 0.76, 6.32, 0.86, 0.06, and 
(a) Reaction of $27 \mathrm{~h}$

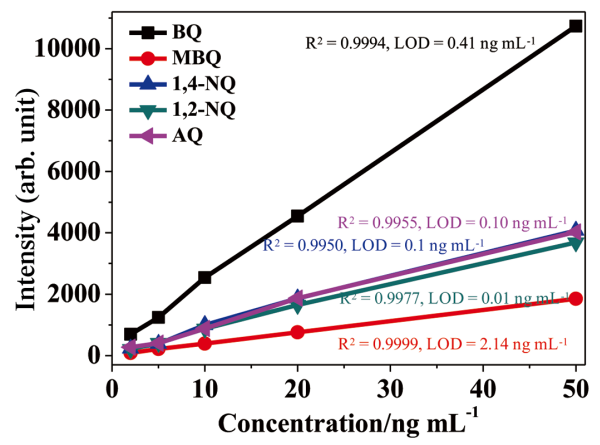

(b) Reaction of $59 \mathrm{~h}$

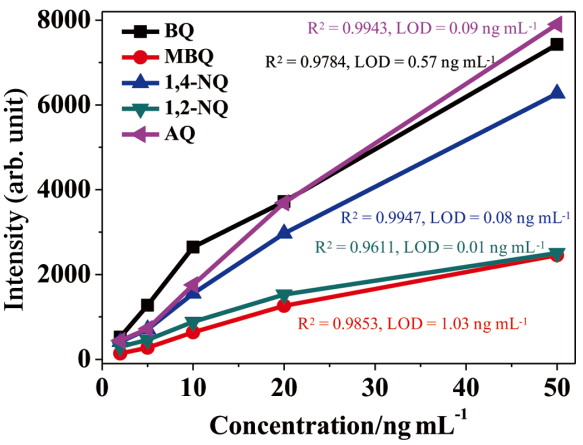

Fig. 3 Linearity curves and LODs for BQ, MBQ, 1,4-NQ, 1,2-NQ, and AQ determination with methanol derivatization for a) 27 and b) $59 \mathrm{~h}$.
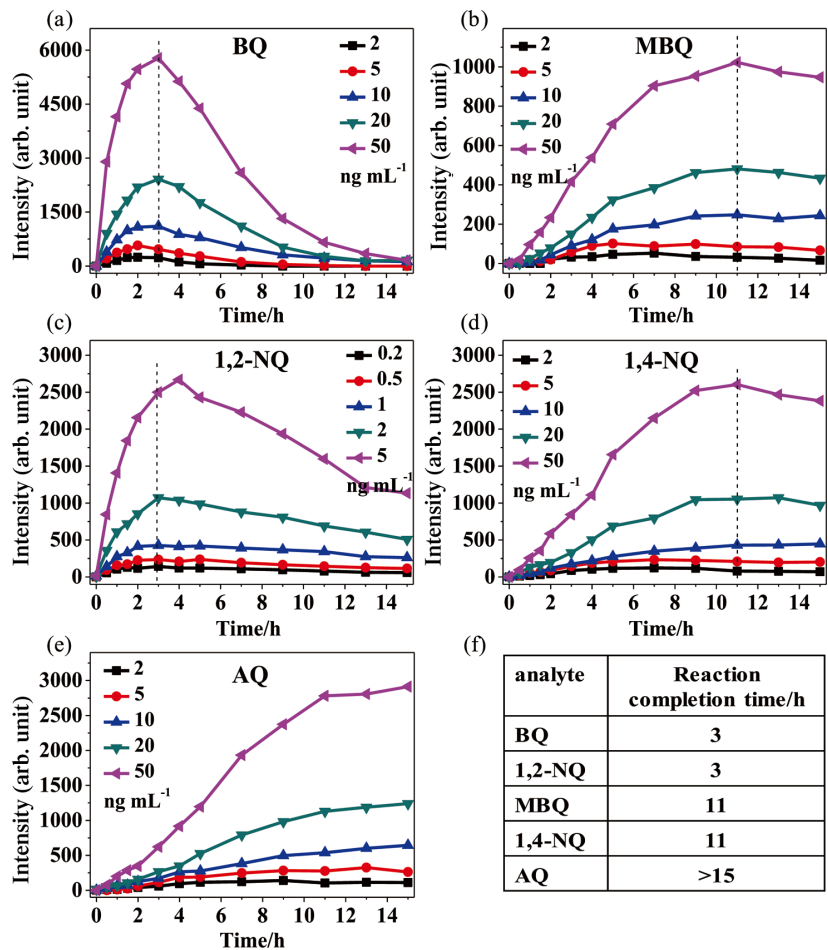

(f)

\begin{tabular}{|c|c|}
\hline \multicolumn{2}{|r|}{ Time/h } \\
\hline analyte & $\begin{array}{c}\text { Reaction } \\
\text { completion time } / \mathrm{h}\end{array}$ \\
\hline BQ & 3 \\
\hline $1,2-N Q$ & 3 \\
\hline MBQ & 11 \\
\hline 1,4-NQ & 11 \\
\hline AQ & $>15$ \\
\hline
\end{tabular}

Table 1 Comparison of the LODs for the five quinones determination under different conditions with our HPLC-ESIMS/MS method

\begin{tabular}{lccl}
\hline \multirow{2}{*}{ Compound } & \multicolumn{3}{c}{ LODs ng mL $\mathrm{mL}^{-1} / \mathrm{pg}$} \\
\cline { 2 - 4 } & $\mathrm{CH}_{3} \mathrm{OH}(27 \mathrm{~h})$ & $\mathrm{CH}_{3} \mathrm{OH}(59 \mathrm{~h})$ & $\mathrm{CH}_{3} \mathrm{OH} / \mathrm{H}_{2} \mathrm{O}(\mathrm{v} / \mathrm{v}, 1: 1)$ \\
\hline $\mathrm{BQ}$ & $0.41 / 0.82$ & $0.57 / 1.14$ & $0.38 / 0.76(3 \mathrm{~h})$ \\
$\mathrm{MBQ}$ & $2.14 / 4.28$ & $1.03 / 2.06$ & $3.16 / 6.32(11 \mathrm{~h})$ \\
$1,4-\mathrm{NQ}$ & $0.1 / 0.2$ & $0.08 / 0.16$ & $0.43 / 0.86(11 \mathrm{~h})$ \\
$1,2-\mathrm{NQ}$ & $0.01 / 0.02$ & $0.01 / 0.02$ & $0.03 / 0.06(3 \mathrm{~h})$ \\
$\mathrm{AQ}$ & $0.1 / 0.2$ & $0.09 / 0.18$ & $0.17 / 0.34(11 \mathrm{~h})$ \\
\hline
\end{tabular}

to a faster hydrolysis of quinones than alcoholysis (Fig. S8) ${ }^{34}$ With the transformation of hydroxylated quinones to methoxylated quinones, the reaction between quinones and methanol might be accelerated. Meanwhile, the signal intensities of methoxylated quinones was decreased for the generation of hydroxylated quinones.

Comparison of the proposed HPLC-ESI-MS/MS method with other method

The LOD comparison of the proposed HPLC-ESI-MS/MS method for quinone determination with other methods is given in Table 2. Our method showed lower LODs than all of the methods, except Toriba's. ${ }^{31}$ Toriba et al. used a silylation reagent to label quinones for GC-MS/MS determination, by which femtogram-level LODs had been achieved. Though the method was especially sensitive for quinone determination, our LC-ESI-MS/MS method could still serve as an alternative owing to the simplicity and economy.

$0.34 \mathrm{pg}$, respectively (Fig. S6), which were $1-5$ times as high as those with methanol as the derivatization reagent (Table 1).

In addition, we investigated the reaction kinetics of five quinones (with quinone concentrations of 5 or $50 \mathrm{ng} \mathrm{mL}^{-1}$ ) with methanol in other solvents, including methanol/water (v/v, 1:9, $3: 7,7: 3$, and 9:1). A trend was observed that the signal intensities of quinone derivatives decreased and the reaction time was shortened when the ratio of water/methanol was increased (Fig. S7). Therefore, improving the ratio of water/ methanol is suggested to shorten the analysis time when the quinone concentrations in samples are high.

The higher LODs and shorter reaction time of quinones with a larger water/methanol ratio might be related to the nucleophilic property of hydroxyl and methoxyl. Hydroxyl possessed a stronger nucleophilic ability than methoxyl, which would lead

\section{Determination of quinones in airborne particulates sample}

To test the practicability of the proposed HPLC-ESI-MS/MS method, we applied it for the determination of quinones in PM2.5 collected in Nanning city. Ultrasonication extraction was used to treat samples. The concentrations of BQ, 1,4-NQ, and 1,2-NQ in PM2.5 were detected to be 390, 29, and $760 \mathrm{pg} \mathrm{m}^{-3}$, respectively, whereas MBQ and 1,4-NQ were not detected (Fig. 5). The results were well in accordance with previous data. ${ }^{21,36}$ Quinones in the atmosphere were reported to be generated from the incomplete combustion of vehicle emissions, exhaust from factories, and cigarettes (primary combustion source) as well as the secondary formation from reactions of polycyclic aromatic hydrocarbons with ozone and 
Table 2 Comparison of the LODs for the five quinones determination of our proposed HPLC-ESI-MS/MS method with other methods

\begin{tabular}{|c|c|c|c|c|c|c|}
\hline & \multirow{2}{*}{ Method } & \multicolumn{5}{|c|}{ LODs/pg } \\
\hline & & BQ & MBQ & $1,4-\mathrm{NQ}$ & $1,2-\mathrm{NQ}$ & AQ \\
\hline Ahmed et al. ${ }^{21}$ & HPLC-chemiluminiscence & & & 2.53 & 3.79 & \\
\hline Valavanidis et al. ${ }^{35}$ & HPLC-photodiode array & $3000-15000$ & $3000-15000$ & $3000-15000$ & & \\
\hline Cho et al. ${ }^{36}$ & GC-MS & & 400 & 300 & & \\
\hline Sousa et al. ${ }^{37}$ & GC-MS & 200 & 10 & 200 & & \\
\hline Alves et al. ${ }^{38}$ & GC-MS & & & 34.92 & & \\
\hline Albinet et al. ${ }^{39}$ & GC-MS & & & & & $0.01-2.6$ \\
\hline María del Rosario Sienra et al. ${ }^{40}$ & GC-MS & & & 9.57 & & \\
\hline Delgado-Saborit et al. ${ }^{41}$ & GC-MS & 7 & 3 & 6 & 11 & \\
\hline Nicol et al. ${ }^{42}$ & GC-MS/MS & & & 8 & & \\
\hline Toriba et al..$^{31}$ & GC-MS/MS & 0.0021 & 0.0012 & 0.001 & 0.0027 & 0.0052 \\
\hline Jakober et al..$^{29}$ & HPLC-APCI-MS & 46 & 17 & 26 & 33 & \\
\hline Delhomme et al. ${ }^{27}$ & LC-APCI-MS/MS & 24 & & 8 & & \\
\hline This study & HPLC-ESI-MS/MS & 0.82 & 4.28 & 0.2 & 0.03 & 0.2 \\
\hline
\end{tabular}

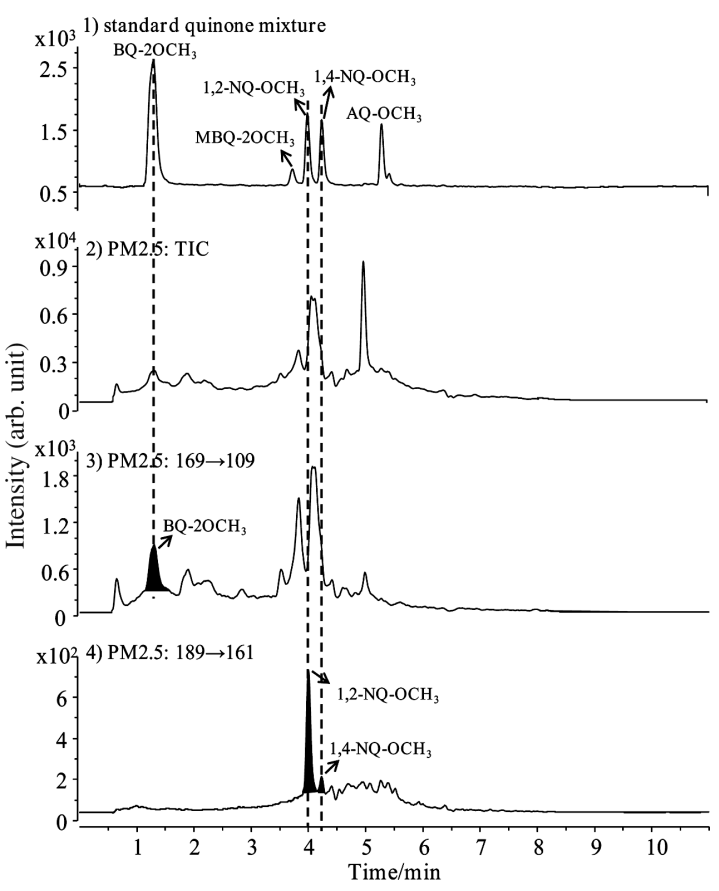

Fig. 5 Determination of the five quinones in PM2.5 collected in Nanning city with the proposed HPLC-ESI-MS/MS method. The concentrations of 1,2-NQ and the other four quinones in the standard mixture are 10 and $100 \mathrm{ng} \mathrm{mL}^{-1}$, respectively.

radical species in the atmosphere. Since the samples were taken from a roadside that was $5 \mathrm{~m}$ away from a busy street with traffic, it was inferred that the quinone pollutants were mainly from vehicle emissions. The chromatograms show that the background noise was high for actual sample analysis. This might be due to interference from the complex matrix (metal ions, inorganic anions, other organic pollutants, etc.) in the samples. Therefore, future work will be focused on the optimization of pretreatment methods for sample purification.

\section{Conclusions}

A simple and economic derivatization method, based on the nucleophilic addition of methanol with quinones, was developed for quinone determination. Through introducing methoxyl "tags" to the quinone structures, the ionization efficiencies of $\mathrm{BQ}, \mathrm{MBQ}, 1,2-\mathrm{NQ}, 1,4-\mathrm{NQ}$, and AQ were greatly improved during ESI-MS. The LODs could be flexibly adjusted by choosing the reaction solvent or changing the reaction time. Finally, the proposed HPLC-ESI-MS/MS method was successfully applied to quinone determination in airborne particulates.

\section{Acknowledgements}

This work was supported by the National Key Basic Research Program of China (No. 2013CB956102), the Guangxi Natural Science Fund Project (No. 2016GXNSFBA380140), the BaGui Scholars Program Foundation (2014) and the National Natural Science Foundation of China (21665003, 41473118).

\section{Supporting Information}

This material is available free of charge on the Web at http:// www.jsac.or.jp/analsci/.

\section{References}

1. E. R. Redfearn and J. Burgos, Nature, 1966, 209, 711.

2. V. A. Morais, D. Haddad, K. Craessaerts, P. J. De Bock, J. Swerts, S. Vilain, L. Aerts, L. Overbergh, A. Grünewald, and P. Seibler, Science, 2014, 344, 203.

3. H. Ishikita and E. W. Knapp, J. Am. Chem. Soc., 2005, 127, 14714.

4. K. Saito, A. W. Rutherford, and H. Ishikita, Proc. Natl. Acad. Sci. U. S. A., 2013, 110, 954.

5. H. Matsumura, K. Umezawa, K. Takeda, N. Sugimoto, T. Ishida, M. Samejima, H. Ohno, M. Yoshida, K. Igarashi, and N. Nakamura, Plos One, 2014, 9, e104851.

6. Y. Gao, X. Chen, L. Fang, F. Liu, R. Cai, C. Peng, and Y. Qi, Free Radical Bio. Med., 2014, 72, 104.

7. C. M. Dawidczyk, L. M. Russell, M. Hultz, and P. C. Searson, Nanomed-Nanotechnol, 2017, 13, 1637.

8. L. E. Cassagnes, P. Perio, G. Ferry, N. Moulharat, M. Antoine, R. Gayon, J. A. Boutin, F. Nepveu, and K. Reybier, Free Radical Bio. Med., 2015, 89, 126. 
9. J. L. Bolton, M. A. Trush, T. M. Penning, G. Dryhurst, and T. J. Monks, Chem. Res. Toxicol., 2000, 13, 135.

10. M. Y. Chung, R. A. Lazaro, D. Lim, J. Jackson, J. Lyon, D. Rendulic, and A. S. Hasson, Environ. Sci. Technol., 2006, $40,4880$.

11. J. G. Charrier, A. S. Mcfall, N. K. Richards-Henderson, and C. Anastasio, Environ. Sci. Technol., 2014, 48, 7010.

12. J. Charrier and C. Anastasio, Environ. Sci. Technol., 2015, 49, 9317.

13. Y. Kumagai, H. Nakajima, K. Midorikawa, S. HommaTakeda, and N. Shimojo, Chem. Res. Toxicol., 1998, 11, 608.

14. J. A. Nykamp, N. C. Bols, and J. C. Carlson, Reprod. Toxicol., 2001, 15, 393.

15. H. Abdollahi and L. Bagheri, Anal. Sci., 2004, 514, 1701.

16. S. M. Ahmed, T. Nagaoka, and K. Ogra, Anal. Sci., 1998, 14, 535 .

17. S. Ahmed, S. Fujii, N. Kishikawa, Y. Ohba, K. Nakashima, and N. Kuroda, J. Chromatogr. A, 2006, 1133, 76.

18. N. Kishikawa, M. Wada, Y. Ohba, K. Nakashima, and N. Kuroda, J. Chromatogr. A, 2004, 1057, 83.

19. T. Kameda, T. Goto, A. Toriba, N. Tang, and K. Hayakawa, J. Chromatogr. A, 2009, 1216, 6758.

20. N. Kishikawa, H. Nakashima, K. Ohyama, K. Nakashima, and N. Kuroda, Talanta, 2010, 81, 1852.

21. S. Ahmed, N. Kishikawa, K. Ohyama, T. Maki, H. Kurosaki, K. Nakashima, and N. Kuroda, J. Chromatogr. A, 2009, 1216, 3977.

22. R. Li, T. Kameda, A. Toriba, K. Hayakawa, and J. M. Lin, Anal. Chem., 2012, 84, 3215.

23. N. Kishikawa, N. Ohkubo, K. Ohyama, K. Nakashima, and N. Kuroda, Anal. Bioanal. Chem., 2009, 393, 1337.

24. N. Kishikawa and N. Kuroda, J. Pharmaceut. Biomed., 2014, 87, 261.

25. C. A. Jakober, M. J. Charles, M. J. Kleeman, and P. G. Green, Anal. Chem., 2006, 78, 5086.

26. J. Lintelmann, K. Fischer, and G. Matuschek, J. Chromatogr. A, 2006, 1133, 241.
27. O. Delhomme, M. Millet, and P. Herckes, Talanta, 2008, $74,703$.

28. X. Zhou, J. Pei, and G. Huang, Rapid Commun. Mass Spectrom., 2015, 29, 100.

29. C. A. Jakober, S. G. Riddle, M. A. Robert, H. Destaillats, M. J. Charles, P. G. Green, and M. J. Kleeman, Environ. Sci. Technol., 2007, 42, 4697.

30. M. Jaoui, T. E. Kleindienst, M. Lewandowski, and E. O. Edney, Anal. Chem., 2004, 76, 4765.

31. A. Toriba, C. Homma, M. Kita, W. Uozaki, Y. Boongla, W. Orakij, N. Tang, T. Kameda, and K. Hayakawa, J. Chromatogr. A, 2016, 1459, 89.

32. R. Ma, J. Hu, Z. Cai, and H. Ju, Anal. Chem., 2014, 86, 8275.

33. J. K. Diedrich and R. R. Julian, Anal. Chem., 2010, 82, 4006.

34. Y. Qian, W. Wang, J. M. Boyd, M. Wu, S. E. Hrudey, and X. F. Li, Environ. Sci. Technol., 2013, 47, 4426.

35. A. Valavanidis, K. Fiotakis, T. Vlahogianni, V. Papadimitriou, and V. Pantikaki, Environ. Chem., 2006, 3, 118.

36. A. K. Cho, E. D. Stefano, Y. You, C. E. Rodriguez, D. A. Schmitz, Y. Kumagai, A. H. Miguel, A. Eiguren-Fernandez, T. Kobayashi, E. Avol, and J. R. Froines, Aerosol Sci. Tech., 2004, 38, 68 .

37. E. T. Sousa, M. P. Cardoso, L. A. Silva, and J. B. D. Andrade, Microchem. J., 2015, 118, 26.

38. C. A. Alves, A. M. P. Vicente, J. Gomes, T. Nunes, M. Duarte, and B. A. M. Bandowe, Atmos. Res., 2016, 180, 128.

39. A. Albinet, E. Leozgarziandia, H. Budzinski, and E. Viilenave, J. Chromatogr. A, 2006, 1121, 106.

40. M. M. D. R. Sienra, Atmos. Environ., 2006, 40, 2374.

41. J. M. Delgado-Saborit, M. S. Alam, K. J. G. Pollitt, C. Stark, and R. M. Harrison, Atmos. Environ., 2013, 77, 974.

42. S. Nicol, J. Dugay, and M. C. Hennion, Chromatographia, 2001, 53, S464. 